\title{
Frequency of symptoms, determinants of severe symptoms, validity of and cut-off score for Menopause Rating Scale (MRS) as a screening tool: A cross-sectional survey among midlife Nepalese women
}

Neena Chuni ${ }^{1,2+}$ and Chandrashekhar T Sreeramareddy $y^{3,4^{*}+}$

\begin{abstract}
Background: Majority of Nepalese women live in remote rural areas, where health services are not easily accessible. We determined the validity of Menopause Rating Scale (MRS) as a screening tool for identification of women with severe menopausal symptoms and cut-off MRS score for referral.

Methods: A cross-sectional survey was carried out between February and August, 2008. Trained health workers administered MRS and a questionnaire to 729 women (40 to 65 years) attending health screening camps in Kaski district of Western Development Region of Nepal. Information about demographics, menopausal status, and use of hormone replacement therapy (HRT), chronic disease, self-perceived general health and reproductive history was also collected. Menopausal status was classified according to the Staging of Reproductive Ageing Workshop (STRAW). We calculated rates of menopausal symptoms, sensitivity, and specificity and likelihood ratios of MRS scores for referral to a gynaecologist. We also carried out multivariate analyses to identify the predictors for referral to a gynaecologist for severe symptoms.

Results: A total 729 women were interviewed. Mean age at menopause was 49.9 years (SD 5.6). Most frequently reported symptoms were, sleeping problems (574, 78.7\%), physical and mental exhaustion (73.5\%), hot flushes (508, $69.7 \%)$, joint and muscular discomfort $(500,68.6 \%)$ and dryness of vagina $(449,61.6 \%)$. Postmenopausal women (247, 33.9\%) and perimenopausal $(215,29.5 \%)$ women together experienced significantly higher prevalence of all symptoms than the premenopausal $(267,36.6 \%)$ women. MRS score of $\geq 16$ had highest ratio for (sensitivity + specificity)/2. Women who reported urogenital symptoms [OR 5.29, 95\% $\mathrm{Cl} 2.59,10.78$ ], and self perceived general health as poor [OR $1.29,95 \% \mathrm{Cl} 1.11,1.53$ ] were more likely to be referred to a gynaecologist for severe menopausal symptoms. While women reporting somatic [OR $0.72,95 \% \mathrm{Cl} 0.63,0.82]$ and psychological [OR 0.86 , $95 \% \mathrm{Cl} 0.74,0.99$ ] symptoms were less likely to be referred.
\end{abstract}

Conclusion: MRS may be used as a screening tool at a cut-off score of $\geq 16$ with least misclassification rate. However, its utility may be limited by woman's general health status and occurrence of urogenital symptoms.

\footnotetext{
* Correspondence: chandrashekharats@yahoo.com

+ Contributed equally

${ }^{3}$ Department of Community Medicine, Manipal Teaching Hospital, Manipal

College of Medical Sciences, Pokhara, Nepal

Full list of author information is available at the end of the article
} 


\section{Background}

Menopause is a condition caused by the depletion of ovarian function followed by cessation of menstruation in women. Modern medicine has significantly prolonged the life span of humans and most women spend one-third to half of their lifetime in post- menopause [1]. Information about menopausal experiences among different racial and ethnic groups is important for healthcare personnel to provide appropriate and specific interventions $[2,3]$. It has been shown that menopausal symptoms vary according to racial groups. For instance, studies have reported that somatic and psychological symptoms are less frequent among Asian women as compared to Caucasian women [4-7]. Further, menopausal symptoms may also vary according to menopausal status. Vasomotor, sexual and psychological symptoms are more frequent among perimenopausal and postmenopausal women [8-10].

During menopause, women often experience some symptoms which may affect their daily activities. In recent years, studies have shown that menopausal symptoms may affect health-related quality of life [11,12]. Menopause Rating Scale (MRS) which is a health related quality of life (HRQOL) scale was developed in the early 1990's in Germany $[13,14]$. Since then, MRS has been well accepted internationally and has been translated into several languages [15] taking international methodological recommendations into consideration [16]. Use of MRS in Turkish language has been validated [17] and also used as an instrument to assess the frequency menopausal symptoms among middle aged women in eastern Malaysia, Northern India, Sri Lanka and Ecuador $[8,10,18,19]$. MRS has a potential of being used as a screening tool to identify those women in need of referral to higher level for severe menopausal symptoms. Such use of MRS would be more appropriate in remote and rural areas of Nepal. In rural Nepal, health care facilities are less accessible to women due to geographic, cultural and social barriers. In such settings, the community health workers may administer MRS to identify the women who are in need of secondary or tertiary level care for severe menopausal symptoms. Therefore it is important to test the validity of MRS as a screening tool. We aimed to determine the frequency of menopausal symptoms among rural Nepalese women; to test the validity of MRS as a screening tool for identification of severe menopausal symptoms; and to determine the cut-off MRS score for referral to specialist consultation. To the best of our knowledge, such study has not been carried out in Nepal.

\section{Methods}

\section{Study design}

A cross-sectional, interviewer administrated questionnaire survey

\section{Setting and participants}

Kaski district is one of the 14 districts in Western Development Region (WDR) of Nepal. In WDR of Nepal most districts are rural and remote, where access to healthcare services and information is very limited. Kaski district has a land area of 2000 squares kilometres and a population of 380, 000. Kaski district has 43 villages and Pokhara sub metropolitan city which has a population of 156, 000 according to the 2001 census [20]. In Nepal, healthcare is offered mainly through Primary Health Centres (PHCs), operated by the Ministry of Health and manned by General Practitioners (GPs), Auxiliary Nurse Midwives (ANMs), Auxiliary Health Workers (AHWs) and health assistants (HAs). Bedabari PHC is adjacent to Pokhara city and Batulechaur Health Post (HP) is a under Bedabari PHC. Each PHC serves a population of 100,000 and HP serves 30,000 population. This study was carried out at afore-mentioned health facilities and the participants were women aged between 40 and 65 years who voluntarily attended the health screening camps.

\section{Instrument}

The questionnaire was divided into four sections (additional files 1 and 2). The first section included the following information about women's socio-demographic characteristics: age, marital status, living situation, education and occupation. The second section included questions about menopausal status at the time of the study, menstrual history and symptoms of dysmenorrhoea experienced in the past. Menopausal status was defined according to STRAW (Stages of Reproductive Aging Workshop) classification. STRAW categorises and defines menopausal women as follows: Premenopause: minor changes in cycle length particularly decreasing length of the cycle. Late perimenopause: had menstruation during the past 2-12 months but not during the past two months. Early perimenopause: had increasing irregularity of menses without skipping periods (7 days difference from the beginning of a given cycle to the next) experienced after the previously regular cycle. Postmenopausal: no menstrual bleeding during the past 12 months $[21,22]$. Early and late perimenopause were combined into perimenopausal stage for our analysis. The third section included questions about presence of any chronic diseases (diabetes, hypertension, bronchial asthma, cardiac disease etc), use of HRT and the women were asked to rate self-perceived general health and wellbeing as good or poor. In the last section women were asked if they had experienced any symptoms based on the MRS, since the age of 40 years. We used the English version of MRS without modification. The original German version of MRS has been translated into English and other 
languages. In all versions, the MRS is a self-administered questionnaire and is widely tested and accepted internationally [13-16]. During the interview women were asked to report symptoms and also asked to rate the severity of symptoms as 'mild', 'moderate', 'severe' or 'very severe' [14]. If any of the symptoms listed in MRS were not reported by women then it was marked as 'none'. MRS score was generated by summing the score given for each of the 11 symptoms. Scoring for each symptom was given as follows: none $=0$, mild $=1$, moderate $=2$, severe $=3$, very severe $=4$.

\section{Ethics and informed consent}

This survey was approved by the research ethics committee of Manipal College of Medical Sciences, Pokhara, Nepal. The women were provided with information about nature of interview to be conducted and participation was voluntary. They were assured about confidentiality of the information to be provided. Informed consent was taken from each eligible woman before the questionnaire interview was administered.

\section{Data collection}

During February 2008 to August 2008, health screening camps were held in Bedabari PHC and Batulechaur HP. We included all women aged between 40 to 65 years. The women were checked for the exclusion criteria during registration process at the reception desk of the camps. The exclusion criteria were the following: pregnant and lactating mothers, women with history of cancer in remission or under treatment currently; history of alcohol or drug abuse and any mental disability or undergoing treatment for psychiatric disorders. Women with premature ovarian failure or known genital malformations were also excluded. If the woman was found eligible, she was invited to participate in the study. To each eligible woman explanation about purpose of the interview was given and informed consent was taken. A face-to-face interview was conducted by paramedical health personnel who were trained about the questionnaire and the English version of MRS. All the interviews took place in the local language, Nepalese.

\section{Statistical Analysis}

Data was coded and entered into Microsoft Excel. The data was converted into SPSS and STATA packages for analysis. We used descriptive statistics to summarise the demographic variables. Frequency of occurrence and severity (as severe and very severe) of symptoms were calculated as percentages. We compared mean ages, MRS scores and severity of symptoms between premenopausal, perimenopausal and postmenopausal status of the women according to STRAW classification. Total MRS Score, and sub scale scores for somatic, psychological and urogenital symptoms were calculated separately. We used non-parametric receiver operating characteristic (ROC) curves command in STATA (version10) to calculate the sensitivity, specificity, positive predictive values and likelihood ratios for different MRS scores to identify the women who are likely be referred to a gynaecologist for severe menopausal symptoms. By this method, we also calculated area under curve (AUC) and its $95 \%$ confidence intervals (95\% CIs) for total MRS score. We also carried out a multivariate analysis on SPSS package (version 14) to find out the predictors for referral to a gynaecologist. Referral to a gynaecologist at least once was considered as a dependant variable. Age, self-reported general health, presence of any chronic disease, regularity of menstrual cycles, history of dysmenorrhoea, history of abortions and scores of MRS sub scales i.e. scores for somatic, psychological and urogenital symptoms were treated as dependant variables.

\section{Results}

\section{Response rates and demographic characteristics}

During the survey period, 1179 women attended the health screening camps. When the eligibility criteria were applied 18 women were either pregnant or were lactating, one woman had received treatment for a genital malignancy and one woman had reached premature menopause (i.e. before 40 years of age). Ninety four women had undergone treatment for chronic psychiatric illness of whom, 62 were chronic alcoholics. Thus 1065 eligible women were invited to participate in the survey interview but 336 women declined to participate. The main reasons for refusal were the need to return back home quickly or non-comprehension about the nature of interview to be carried out. We interviewed 729 women giving a response rate of $68.5 \%$ (729/1065). Demographic characteristics of the women are shown in table 1. Mean age of the women interviewed was 49.9 years $(\mathrm{SD}=5.6)$. Median age was 49 years (lower quartile i.e. Q1 \& upper quartile i.e. Q3 were 46 and 53 years respectively). Mean age of the women according to menopausal status (classified according to STRAW) were as follows: premenopausal 45.1 years $(\mathrm{SD}=2.78)$, perimenopausal 49.14 years $(\mathrm{SD}=$ $2.01)$, postmenopausal 55.67 years $(S D=5.6)$. Majority $(88.6 \%)$ of the women were currently married. Of these, 574 (78.7\%) women were living with their husbands. The women we interviewed were mostly illiterates (468, $64.9 \%$ ) and mainly housewives (528, 72.4\%).

\section{Health status and frequency of menopausal symptoms}

One hundred and eighty six women (25.5\%) rated their general health as poor, while 127 (17.4\%) women had one or more chronic disease. The main chronic diseases the women had were Chronic Obstructive Pulmonary Disease (58), hypertension (34), diabetes (26), others (9) 
Table 1 Socio-demographic profile of the participants

\begin{tabular}{lll}
\hline Characteristic & Number & Percentage \\
\hline Age & & \\
\hline $40-44$ & 130 & 17.8 \\
\hline $45-49$ & 269 & 36.9 \\
\hline $50-54$ & 195 & 26.7 \\
\hline $55-59$ & 70 & 9.6 \\
\hline $60-64$ & 65 & 8.9
\end{tabular}

\begin{tabular}{lll}
\hline Marital status & & \\
\hline Currently married & 646 & 88.6 \\
\hline Divorced & 28 & 3.8 \\
\hline Widowed & 54 & 7.4 \\
\hline
\end{tabular}

\begin{tabular}{lll}
\hline Education level & & \\
\hline Illiterate & 468 & 64.9 \\
\hline Primary level & 121 & 16.6 \\
\hline Secondary level & 93 & 12.8 \\
\hline Tertiary level & 47 & 6.4
\end{tabular}

\begin{tabular}{lll}
\hline Living situation & & \\
\hline With partner & 574 & 78.7 \\
\hline With children/others & 150 & 20.6 \\
\hline Alone & 4 & 0.5 \\
\hline Occupation & \\
\hline Housewife & 528 & 72.4 \\
\hline General worker & 154 & 21.1 \\
\hline Semi professional & 42 & 5.8 \\
\hline Professional & 5 & 0.7 \\
\hline
\end{tabular}

Seventy five (10.3\%) women reported that they had visited a gynaecologist for menopausal symptoms and $21(2.9 \%)$ of them had undergone hormone replacement therapy. Frequency and severity of the menopausal symptoms are shown in table 2 . Most frequent somatic symptoms were sleeping problems, $(574,78.7 \%)$ hot flushes $(508,69.7 \%)$ and joint and muscular discomfort (500, 68.6\%). Among psychological symptoms, physical and mental exhaustion were reported by 536 (73.5\%) women. Among the urogenital symptoms, dryness of vagina was reported by 449 (61.6\%) women and 385 (52.8\%) women reported bladder problems. Among all the menopausal symptoms, hot flushes were perceived as severe $(157,21.5 \%)$ and very severe $(75,10.3 \%)$. Other symptoms that were perceived as severe were: anxiety $(114,15.6 \%)$, depressive $\operatorname{mood}(109,14.9 \%)$, irritability $(105,14.4 \%)$, dryness of vagina $(102,13.9 \%)$. The differences between three groups of menopausal status for all the symptoms were statistically significant (Table 3). MRS score including the sub scale scores and severity of symptoms were significantly higher among postmenopausal women than the perimenopausal and premenopausal women (table 4).
Table 2 Frequency and severity of menopausal symptoms

\begin{tabular}{llll}
\hline Menopausal symptoms & Number (\%) & Severe & Very severe \\
\hline Somatic & & & \\
\hline Sleeping problems & $574(78.7)$ & 93 & 1 \\
\hline Hot flushes, sweating & $508(69.7)$ & 157 & 75 \\
\hline Joint and muscular discomfort & $500(68.6)$ & 86 & 0 \\
\hline Heart discomfort & $360(49.4)$ & 0 & 0 \\
\hline Psychological & & & \\
\hline Physical and mental exhaustion & $536(73.5)$ & 68 & 4 \\
\hline Depressive mood & $402(55.2)$ & 109 & 12 \\
\hline Irritability & $339(46.5)$ & 105 & 10 \\
\hline Anxiety & $334(45.8)$ & 114 & 7 \\
\hline Urogenital & & & \\
\hline Dryness of vagina & $449(61.6)$ & 102 & 4 \\
\hline Bladder problems & $385(52.8)$ & 38 & 2 \\
\hline Sexual problems & $343(47.1)$ & 56 & 6 \\
\hline
\end{tabular}

\section{Predictors of severe menopausal symptoms}

Table 5 shows the predictors for referral to a gynaecologist for evaluation of severe menopausal symptoms by univariate and multivariate analyses. On univariate analysis, self-reported poor general health, presence of chronic disease, irregular menstrual cycles, dysmenorrhoea and occurrence of all three groups of menopausal symptoms were associated with referral to a gynaecologist. On multivariate analysis, women reporting poor general health (OR 5.29, 95\% CI 2.59 10.78) were likely to be referred. Among menopausal symptoms women reporting somatic (OR $0.72,95 \%$ CI 0.630 .82 ) and psychological (OR $0.86,95 \%$ CI 0.74 0.99) symptoms were less likely to be referred. Women reporting urogenital (OR 1.29, 95\% 1.11 1.53) symptoms were more likely to be referred to a gynaecologist for further evaluation.

\section{Validity of MRS as a screening tool}

The sensitivity, specificity, positive predictive values and likelihood ratios for different MRS scores to identify the women who are likely to be referred to a gynaecologist for severe menopausal symptoms are shown in table 6 and in Figure 1 by non-parametric receiver operating characteristic (ROC) curves. The area under the curve (AUC) was calculated using the non-parametric method of De Long. We chose an optimum cut-off point at a total MRS score where the ratio (sensitivity + specificity) $/ 2$ was highest. At this point the lowest total misclassification error rate was expected [23]. This criterion was chosen to allow for comparison with previous studies available in the literature [24]. The optimal cutoff MRS score for referral to gynaecologist was 16 . The area under curve was 0.79 (95\% CI 0.740 .84$)$. 
Table 3 Distribution of menopausal symptoms according to menopausal status

\begin{tabular}{|c|c|c|c|c|}
\hline Menopausal symptoms & All (\%) $N=729$ & $\begin{array}{c}\text { Premenopause } \\
\mathrm{N}=267\end{array}$ & $\begin{array}{c}\text { Perimenopause } \\
\mathrm{N}=215\end{array}$ & $\begin{array}{l}\text { Post menopause } \\
\quad N=247\end{array}$ \\
\hline \multicolumn{5}{|l|}{ Somatic } \\
\hline Sleeping problems & $574(78.7)$ & $160(59.9)$ & $185(86.1)$ & $229(92.7)$ \\
\hline Hot flushes, sweating & $508(69.7)$ & $61(22.8)$ & $204(94.9)$ & $243(98.4)$ \\
\hline Joint and muscular discomfort & $500(68.6)$ & $130(48.7)$ & $167(77.7)$ & $203(82.2)$ \\
\hline Heart discomfort & $360(49.4)$ & $81(30.3)$ & $111(51.6)$ & $168(68.0)$ \\
\hline \multicolumn{5}{|l|}{ Psychological } \\
\hline Physical \& mental exhaustion & $536(73.5)$ & $153(57.3)$ & $171(79.5)$ & $212(85.8)$ \\
\hline Depressive mood & $402(55.2)$ & $112(41.9)$ & $138(64.2)$ & $152(61.5)$ \\
\hline Irritability & $339(46.5)$ & $60(22.5)$ & $134(62.3)$ & $145(58.7)$ \\
\hline Anxiety & $334(45.8)$ & $90(33.7)$ & $104(48.4)$ & $140(56.7)$ \\
\hline \multicolumn{5}{|l|}{ Urogenital } \\
\hline Dryness of vagina & 449 (61.6) & $61(22.8)$ & $173(80.5)$ & $215(87.1)$ \\
\hline Bladder problems & $385(52.8)$ & $92(34.5)$ & $128(59.5)$ & $165(66.8)$ \\
\hline Sexual problems & $343(47.1)$ & $111(41.6)$ & $166(77.2)$ & $199(80.6)$ \\
\hline
\end{tabular}

* All comparisons were statistically significant $(p<0.01)$ by chi square test

\section{Discussion}

Our health facility-based survey among midlife women with an interviewer administered MRS could identify the frequency and severity of menopausal symptoms among rural and largely illiterate women. MRS fared well as a screening instrument and a total MRS score of 16 and above could be considered as an optimal cut-off point for referral to a gynecologist. However, sub scale score for urogenital symptoms was a better predictor for referral to a gynaecologist. The optimistic results of our survey on a relatively large sample of women should be interpreted carefully in the light of some limitations we had. The sample of women we surveyed, were from catchment area of two health facilities where the women's health camps were held. This makes our sample non-representative of Nepalese women, thus limiting the external validity. Further, all women may not have correctly recalled the symptoms listed in the MRS and about referral to a gynaecologist for evaluation of severe menopausal symptoms. There may also have been an element of subjectivity while assessing the severity of symptoms. Response rates were not high mainly due to crowding caused during free of cost health camps and lack of comprehension by lesser educated women. So there may have been some selection bias.

The prevalence and proportion of menopausal symptoms may vary according to racial and ethnic groups. Population-based surveys among Caucasian populations have reported a higher prevalence (40 -70\%) [25-27] while those from Asian countries have reported a lower prevalence (10-50\%) [6]. Three studies from Turkey have reported varying prevalence (35-90\%) [28-30]. In our survey, though all symptoms were reported, the proportion of women reporting symptoms listed in MRS varied. Sleep disorders, physical and mental exhaustion were most common symptoms. Prevalence of hot flushes and sweating in our survey was nearly same as prevalence reported from western countries. Though hot flushes was not a common symptom was perceived as 'severe' and 'very severe'. Hot flushes, sweating, vaginal dryness and sleep disturbances are considered the main climacteric complaints in western countries [31-33]. Similarly, hot flushes and sweating were the most common complaints among Turkish women [34].

Table 4 Comparison of MRS scores and severe menopausal symptoms according to the menopausal status

\begin{tabular}{lcccc}
\hline Variable & $\begin{array}{c}\text { Premenopause } \\
\mathbf{N}=\mathbf{2 6 7}\end{array}$ & $\begin{array}{c}\text { Perimenopause } \\
\mathbf{N}=\mathbf{2 1 5}\end{array}$ & $\begin{array}{c}\text { Postmenopause } \\
\mathbf{N}=\mathbf{2 4 7}\end{array}$ & $\mathbf{p}$-value \\
\hline Total MRS score (Mean \& SD) & $5.3(3.79)$ & $12.28(3.36)$ & $16.24(4.81)$ & $<0.001^{*}$ \\
\hline Somatic symptoms (Mean \& SD) & $2.17(2.06)$ & $5.27(1.96)$ & $7.17(2.34)$ & $<0.001^{*}$ \\
\hline Psychological symptoms (Mean \& SD) & $1.82(1.31)$ & $3.61(1.60)$ & $4.36(2.12)$ & $4.72(2.11)$ \\
\hline Urogenital symptoms (Mean \& SD) & $1.30(1.51)$ & $3.39(1.70)$ & $154(62.3)$ & $<0.001^{*}$ \\
\hline Severe symptoms (Number and percentage) & $8(2.9)$ & $41(19.1)$ & 0.001 \\
\hline
\end{tabular}

* ANOVA test $\alpha$ Chi square test 
Table 5 Multivariate analysis of predictors of referral to a gynaecologist for evaluation of severe menopausal symptoms

\begin{tabular}{|c|c|c|c|c|}
\hline Variable & $\begin{array}{l}\text { Univariate } \\
\text { OR }(95 \% \mathrm{Cl})\end{array}$ & p-value & $\begin{array}{c}\text { Adjusted } \\
\text { OR }(95 \% \mathrm{Cl})\end{array}$ & $p$-value \\
\hline Age & $\begin{array}{c}0.89 \\
(0.86,0.93) \\
\end{array}$ & $<0.001$ & $\begin{array}{c}1.01 \\
(0.94,1.07) \\
\end{array}$ & 0.859 \\
\hline \multicolumn{5}{|l|}{ General health } \\
\hline Good & 1 & & 1 & \\
\hline Poor & $\begin{array}{c}10.16 \\
(5.93,17.43)\end{array}$ & $<0.001$ & $\begin{array}{c}5.29 \\
(2.59,10.78)\end{array}$ & $<0.001$ \\
\hline \multicolumn{5}{|l|}{ Chronic disease } \\
\hline No & 1 & & 1 & \\
\hline Yes & $\begin{array}{c}1.86 \\
(1.07,3.23)\end{array}$ & 0.028 & $\begin{array}{c}1.54 \\
(0.78,3.04)\end{array}$ & 0.21 \\
\hline \multicolumn{5}{|c|}{ Regular menstrual cycles } \\
\hline Yes & 1 & & 1 & \\
\hline No & $\begin{array}{c}6.63 \\
(2.83,15.48) \\
\end{array}$ & $<0.001$ & $\begin{array}{c}0.53 \\
(0.19,1.46) \\
\end{array}$ & 0.217 \\
\hline \multicolumn{5}{|l|}{ Dysmenorrhea } \\
\hline No & 1 & & 1 & \\
\hline Yes & $\begin{array}{c}2.04 \\
(1.05,3.96)\end{array}$ & 0.035 & $\begin{array}{c}0.97 \\
(0.44,2.15)\end{array}$ & 0.939 \\
\hline \multicolumn{5}{|l|}{ Abortions } \\
\hline None & 1 & & 1 & \\
\hline One or more & $\begin{array}{c}1.25 \\
(0.74,2.10)\end{array}$ & 0.402 & $\begin{array}{c}0.90 \\
(0.49,1.64)\end{array}$ & 0.736 \\
\hline \multicolumn{5}{|c|}{ Menopausal symptoms } \\
\hline $\begin{array}{c}\text { Somatic } \\
\text { symptoms }\end{array}$ & $\begin{array}{c}0.64 \\
(0.57,0.71) \\
\end{array}$ & $<0.001$ & $\begin{array}{c}0.72 \\
(0.63,0.82) \\
\end{array}$ & $<0.001$ \\
\hline $\begin{array}{l}\text { Psychological } \\
\text { symptoms }\end{array}$ & $\begin{array}{c}0.67 \\
(0.60,0.76)\end{array}$ & $<0.001$ & $\begin{array}{c}0.86 \\
(0.74,0.99)\end{array}$ & 0.046 \\
\hline $\begin{array}{l}\text { Urogenital } \\
\text { symptoms }\end{array}$ & $\begin{array}{c}0.81 \\
(0.73,0.89)\end{array}$ & $<0.001$ & $\begin{array}{c}1.29 \\
(1.11,1.53)\end{array}$ & 0.001 \\
\hline
\end{tabular}

In our survey, hot flushes and sleep disorders were the most common symptoms among both perimenopausal and postmenopausal women. These symptoms can be explained by the physiological fluctuations in oestrogen levels. Similar results were reported from studies carried out among Caucasian, Australian and South-east Asian women [35-38,38,39]. The probability for occurrence of other symptoms is higher if the woman had experienced vasomotor symptoms [40]. Several studies from Asian countries have also reported a lower prevalence of classical menopausal symptoms [35-38,41-44]. Such variability of menopausal symptoms is not well known. This may be due to woman's attitude and awareness, or socio-cultural and economic factors.

Symptoms reported during mid-life may also be influenced by various factors [45]. These may be due to increased levels of physical and mental stress requiring support and coping mechanisms. Socio-cultural milieu and economic factors may also affect these support and
Table 6 Sensitivity, Specificity, positive predictive values and likelihood ratios for predicting the women who should likely be referred to a gynaecologist for evaluation of severe menopausal symptoms

\begin{tabular}{|c|c|c|c|c|c|}
\hline $\begin{array}{l}\text { Cut-off } \\
\text { point }\end{array}$ & Sensitivity & Specificity & $\begin{array}{l}\text { Correctly } \\
\text { classified }\end{array}$ & LR+ & LR- \\
\hline$(>=1)$ & $100.00 \%$ & $0.00 \%$ & $10.29 \%$ & 1 & \\
\hline$(>=2)$ & $100.00 \%$ & $1.38 \%$ & $11.52 \%$ & 1.014 & 0 \\
\hline$(>=3)$ & $100.00 \%$ & $8.26 \%$ & $17.70 \%$ & 1.09 & 0 \\
\hline$(>=4)$ & $100.00 \%$ & $14.98 \%$ & $23.73 \%$ & 1.1763 & 0 \\
\hline$(>=5)$ & $100.00 \%$ & $24.62 \%$ & $32.37 \%$ & 1.3266 & 0 \\
\hline$(>=6)$ & $98.67 \%$ & $30.12 \%$ & $37.17 \%$ & 1.412 & 0.0443 \\
\hline$(>=7)$ & $97.33 \%$ & $34.71 \%$ & $41.15 \%$ & 1.4908 & 0.0768 \\
\hline$(>=8)$ & $93.33 \%$ & $36.39 \%$ & $42.25 \%$ & 1.4673 & 0.1832 \\
\hline$(>=9)$ & $88.00 \%$ & $40.83 \%$ & $45.68 \%$ & 1.4871 & 0.2939 \\
\hline$(>=10)$ & $88.00 \%$ & $44.34 \%$ & $48.83 \%$ & 1.5811 & 0.2706 \\
\hline$(>=11)$ & $86.67 \%$ & $48.32 \%$ & $52.26 \%$ & 1.6769 & 0.2759 \\
\hline$(>=12)$ & $85.33 \%$ & $53.98 \%$ & $57.20 \%$ & 1.8541 & 0.2717 \\
\hline$(>=13)$ & $81.33 \%$ & $61.31 \%$ & $63.37 \%$ & 2.1025 & 0.3044 \\
\hline$(>=14)$ & $78.67 \%$ & $67.74 \%$ & $68.86 \%$ & 2.4383 & 0.3149 \\
\hline$(>=15)$ & $72.00 \%$ & $72.32 \%$ & $72.29 \%$ & 2.6015 & 0.3871 \\
\hline$(>=16)$ & $69.33 \%$ & $76.91 \%$ & $76.13 \%$ & 3.0029 & 0.3987 \\
\hline$(>=17)$ & $62.67 \%$ & $82.42 \%$ & $80.38 \%$ & 3.5638 & 0.453 \\
\hline$(>=18)$ & $49.33 \%$ & $88.07 \%$ & $84.09 \%$ & 4.1364 & 0.5753 \\
\hline$(>=19)$ & $41.33 \%$ & $90.37 \%$ & $85.32 \%$ & 4.2908 & 0.6492 \\
\hline$(>=20)$ & $26.67 \%$ & $93.58 \%$ & $86.69 \%$ & 4.1524 & 0.7837 \\
\hline$(>=21)$ & $18.67 \%$ & $95.57 \%$ & $87.65 \%$ & 4.2097 & 0.8511 \\
\hline$(>=22)$ & $16.00 \%$ & $97.09 \%$ & $88.75 \%$ & 5.5074 & 0.8651 \\
\hline$(>=23)$ & $10.67 \%$ & $98.17 \%$ & $89.16 \%$ & 5.8133 & 0.91 \\
\hline$(>=24)$ & $6.67 \%$ & $98.47 \%$ & $89.03 \%$ & 4.36 & 0.9478 \\
\hline$(>=25)$ & $5.33 \%$ & $99.08 \%$ & $89.44 \%$ & 5.8134 & 0.9554 \\
\hline$(>=26)$ & $0.00 \%$ & $99.69 \%$ & $89.44 \%$ & 0 & 1.0031 \\
\hline$(>=28)$ & $0.00 \%$ & $99.85 \%$ & $89.57 \%$ & 0 & 1.0015 \\
\hline$(>28)$ & $0.00 \%$ & $100.00 \%$ & $89.71 \%$ & & 1 \\
\hline
\end{tabular}

coping mechanisms. Reports suggest that menopausal symptoms may also be confounded by symptoms attributable to genetic factors and aging per se [32]. Therefore, the symptoms reported may not be attributable to climacteric itself. This argument may be supported by our results, where the commonest symptoms reported by premenopausal women were physical and mental exhaustion and sleep disorders. All premenopausal women had reported symptoms given in the MRS questionnaire. Our findings support the view that symptoms experienced by these women may have originated from physical and psychological problems the women had but not as a menopausal symptom alone $[1,46]$. The proportion of women reporting their general health as poor and visiting a gynaecologist for their menopausal symptoms was only a tenth. However the same proportions 


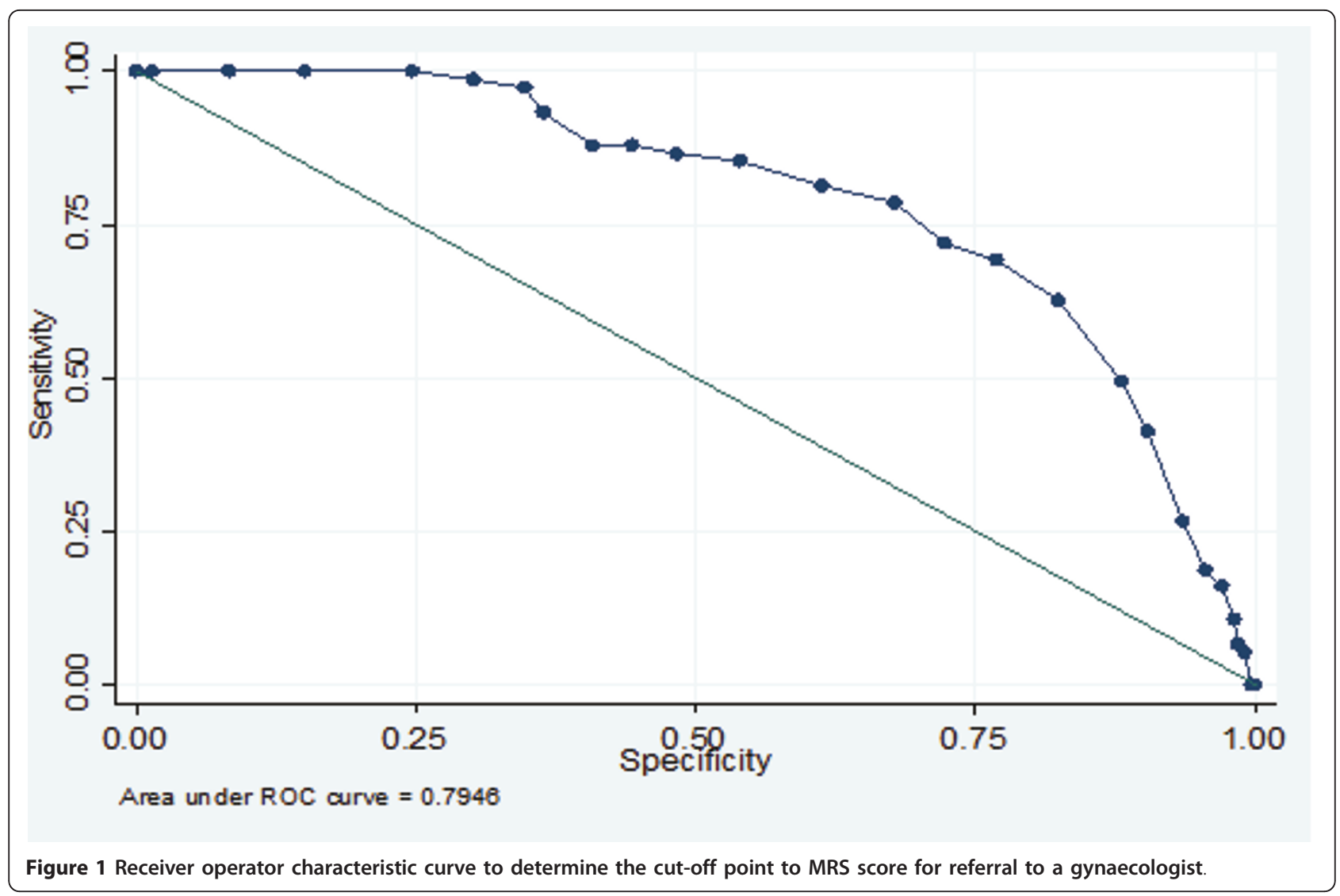

were nearly a third in studies reported from Turkey $[30,47]$.

On multivariate analysis, women who reported their general health as poor were likely to be referred to a gynaecologist for evaluation. Similar results have been reported by other studies $[17,18,48]$. We found that women reporting urogenital symptoms were more likely to be referred to a gynaecologist for further evaluation. Women with somatic and psychological symptoms were less likely to be referred to a gynaecologist for evaluation of symptoms. Women with psychological and somatic symptoms may not have attributed their symptoms to menopause. As we discussed above these somatic and psychological symptoms may be as result of physical and psychological stress, these rural women experience during midlife. Therefore, the women may have over-rated their symptoms as menopausal symptoms when MRS was administered to them. On the contrary to the report from Turkey, presence of a chronic disease was not a predictor for referral to a gynaecologist. We expect that self-reported health status and presence of chronic disease may have confounded the predictors of referral for severe menopausal symptoms. Use of MRS instrument as a screening tool may be affected by these confounding factors as discussed above. Urogenital symptoms seem to be more specific than the psychological and somatic symptoms. This result should be verified by future studies minimising the misreporting of menopausal symptoms when MRS is administered. The optimal cut-off for MRS score we obtained for referral to a gynaecologist was $\geq 16$ and the sensitivity and specificity values at this cut-off are comparable to those reported from MRS validation study [49] and indicate a better reliability than a similar study from reported from Turkey [17]. The method we adopted to determine the cut-off score was in accordance to literature available about validation of screening instruments in rural areas. To our knowledge, there are very few studies which have tested the validity of MRS as screening tool. The potential utility of MRS as a screening instrument to be administered by paramedical workers should be further established. However, such potential utility appears to be limited by misclassification of somatic and psychological symptoms arising from other causes as 'menopausal'. Utility of MRS as a screening instrument should be carefully considered to avoid too many false positives being referred for evaluation of severe menopausal symptoms. Such excess referrals may cause an additional burden on medical personnel in resource-limited rural settings like Nepal. 


\section{Conclusion}

The symptoms reported by the women according to MRS were concordant to the existing literature about the utility of MRS to assess menopausal symptoms. Though symptoms reported were similar to those reported by women from other Asian countries, there may have been over-reporting of some psychological and somatic symptoms. Urogenital symptoms appear to be more specific for referral to a gynaecologist. Further studies are required to confirm or refute the utility of MRS as a screening instrument.

\section{Additional material}

Additional file 1: Questionnaire used for the survey Socio-

demographic information, Reproductive history, STRAW

classification and chronic disease information

Additional file 2: English Version of Menopause Rating Scale. Eleven questions about menopausal symptoms and their severity in a five point Likert scale.

\section{Acknowledgements}

We thank the administrative staff and medical interns of Manipal College of Medical Sciences for their support rendered to carry out this study. We also thank the staff of Bedabari Primary Health Center and Batulechaur Health Post for their assistance during the survey.

\section{Author details}

'Department of Obstetrics and Gynaecology, Manipal Teaching Hospital, Manipal College of Medical Sciences, Pokhara, Nepal. ²Department of Obstetrics and Gynaecology, Indira Gandhi Memorial Hospital, Male, Maldives. ${ }^{3}$ Department of Community Medicine, Manipal Teaching Hospital, Manipal College of Medical Sciences, Pokhara, Nepal. ${ }^{4}$ Department of Community Medicine, Melaka Manipal Medical College, Jalan Batu Hampar, Bukit Baru, Melaka, Malaysia.

\section{Authors' contributions}

NC conceived the study, designed the questionnaire, collected the data and co-drafted the manuscript for publication. CTS contributed to the study design, conducted data analysis and interpreted the results and co-drafted manuscript for publication. Both authors read and approved the final manuscript to be submitted for publication.

\section{Competing interests}

The authors declare that they have no competing interests.

Received: 20 December 2010 Accepted: 14 June 2011 Published: 14 June 2011

\section{References}

1. World Health Organisation (WHO): Scientific Group on Research on the Menopause in the 1990s. Research on the menopause: Report of a WHO scientific group. WHO technical report series Geneva: WHO866; 1990.

2. Rotem M, Kushnir T, Levine R, Ehrenfeld M: A psycho-educational program for improving women's attitudes and coping with menopause symptoms. J Obstet Gynecol Neonatal Nurs 2005, 34:233-240.

3. Twiss JJ, Wegner J, Hunter M, Kelsay M, Rathe-Hart M, Salado W: Perimenopausal symptoms, quality of life, and health behaviors in users and nonusers of hormone therapy. J Am Acad Nurse Pract 2007, 19:602-613.

4. Oddens BJ, Boulet MJ, Lehert P, Visser AP: Has the climacteric been medicalized? A study on the use of medication for climacteric complaints in four countries. Maturitas 1992, 15:171-181.
5. Pan HA, Wu MH, Hsu CC, Yao BL, Huang KE: The perception of menopause among women in Taiwan. Maturitas 2002, 41:269-274.

6. Boulet MJ, Oddens BJ, Lehert P, Vemer HM, Visser A: Climacteric and menopause in seven South-east Asian countries. Maturitas 1994, 19:157-176.

7. Fuh JL, Wang SJ, Lu SR, Juang KD, Chiu LM: The Kinmen women-health investigation (KIWI): a menopausal study of a population aged 40-54. Maturitas 2001, 39:117-124

8. Waidyasekera H, Wijewardena K, Lindmark G, Naessen T: Menopausal symptoms and quality of life during the menopausal transition in Sri Lankan women. Menopause 2009, 16:164-170.

9. Chim H, Tan BH, Ang CC, Chew EM, Chong YS, Saw SM: The prevalence of menopausal symptoms in a community in Singapore. Maturitas 2002, 41:275-282.

10. Rahman SA, Zainudin SR, Mun VL: Assessment of menopausal symptoms using modified Menopause Rating Scale (MRS) among middle age women in Kuching, Sarawak, Malaysia. Asia Pac Fam Med 2010, 9:5.

11. Budakoglu II, Ozcan C, Eroglu D, Yanik F: Quality of life and postmenopausal symptoms among women in a rural district of the capital city of Turkey. Gynecol Endocrinol 2007, 23:404-409.

12. Chedraui P, Blumel JE, Baron G, Belzares E, Bencosme A, Calle A, et al: Impaired quality of life among middle aged women: a multicentre Latin American study. Maturitas 2008, 61:323-329.

13. Hauser GA, Huber IC, Keller PJ, Lauritzen C, Schneider HP: [Evaluation of climacteric symptoms (Menopause Rating Scale)]. Zentralbl Gynakol 1994, 116:16-23.

14. Hauser GA: [A new rating scale for the climacteric syndrome (Menopause Rating Scale (MRS)]. Schweiz Med Wochenschr 1997, 127:122-127.

15. Heinemann LA, Potthoff P, Schneider HP: International versions of the Menopause Rating Scale (MRS). Health Qual Life Outcomes 2003, 1:28.

16. Heinemann K, Ruebig A, Potthoff $P$, Schneider HP, Strelow F, Heinemann LA, et al: The Menopause Rating Scale (MRS) scale: a methodological review. Health Qual Life Outcomes 2004, 2:45.

17. Metintas S, Arykan I, Kalyoncu C, Ozalp S: Menopause Rating Scale as a screening tool in rural Turkey. Rural Remote Health 2010, 10:1230.

18. Kakkar V, Kaur D, Chopra K, Kaur A, Kaur IP: Assessment of the variation in menopausal symptoms with age, education and working/non-working status in north-Indian sub population using menopause rating scale (MRS). Maturitas 2007, 57:306-314.

19. Chedraui P, Aguirre W, Hidalgo L, Fayad L: Assessing menopausal symptoms among healthy middle aged women with the Menopause Rating Scale. Maturitas 2007, 57:271-278.

20. Central Bureau of Statistics NPCS: District Development Profile. Nepal: His Majesty Government; 2001; 2001, Ref Type: Report.

21. Soules MR, Sherman S, Parrott E, Rebar R, Santoro N, Utian W, et al: Executive summary: Stages of Reproductive Aging Workshop (STRAW). Climacteric 2001, 4:267-272.

22. Soules MR, Sherman S, Parrott E, Rebar R, Santoro N, Utian W, et al: Stages of Reproductive Aging Workshop (STRAW). J Womens Health Gend Based Med 2001, 10:843-848.

23. Youden WJ: Index for rating diagnostic tests. Cancer 1950, 3:32-35.

24. Sreeramareddy CT, Chuni N, Patil R, Singh D, Shakya B: Anthropometric surrogates to identify low birth weight Nepalese newborns: a hospitalbased study. BMC Pediatr 2008, 8:16.

25. Avis NE, Crawford SL, MCKinlay SM: Psychosocial, behavioral, and health factors related to menopause symptomatology. Womens Health 1997, 3:103-120.

26. Dennerstein L, Smith AM, Morse C, Burger H, Green A, Hopper J, et al: Menopausal symptoms in Australian women. Med J Aust 1993, 159:232-236.

27. Nedstrand E, Pertl J, Hammar M: Climacteric symptoms in a postmenopausal Czech population. Maturitas 1996, 23:85-89.

28. Discigil G, Gemalmaz A, Tekin N, Basak O: Profile of menopausal women in west Anatolian rural region sample. Maturitas 2006, 55:247-254.

29. Neslihan CS, Bilge SA, Ozturk TN, Oya G, Ece O, Hamiyet B: The menopausal age, related factors and climacteric symptoms in Turkish women. Maturitas 1998, 30:37-40.

30. Uncu Y, Alper Z, Ozdemir H, Bilgel N, Uncu G: The perception of menopause and hormone therapy among women in Turkey. Climacteric 2007, 10:63-71 
31. Berg JA, Taylor DL: Symptom experience of Filipino American midlife women. Menopause 1999, 6:105-114.

32. Hemminki E, Topo P, Kangas I: Experience and opinions of climacterium by Finnish women. Eur J Obstet Gynecol Reprod Biol 1995, 62:81-87.

33. Woods NF, Mitchell ES: Symptoms during the perimenopause: prevalence, severity, trajectory, and significance in women's lives. Am J Med 2005, , 118 Suppl 12B: 14-24.

34. Ayranci U, Orsal O, Orsal O, Arslan G, Emeksiz DF: Menopause status and attitudes in a Turkish midlife female population: an epidemiological study. BMC Womens Health 2010, 10:1.

35. Takeshi A: First Consensus Meeting on Menopause in the East Asian Region: Demography of the menopause and pattern of climacteric symptoms in the East Asian region. 2003.

36. Lam PM, Leung TN, Haines C, Chung TK: Climacteric symptoms and knowledge about hormone replacement therapy among Hong Kong Chinese women aged 40-60 years. Maturitas 2003, 45:99-107.

37. Loh FH, Khin LW, Saw SM, Lee JJ, Gu K: The age of menopause and the menopause transition in a multiracial population: a nation-wide Singapore study. Maturitas 2005, 52:169-180.

38. McKinlay SM, Brambilla DJ, Posner JG: The normal menopause transition. Maturitas 2008, 61:4-16.

39. Guthrie JR, Dennerstein L, Taffe JR, Lehert P, Burger HG: The menopausal transition: a 9-year prospective population-based study. The Melbourne Women's Midlife Health Project. Climacteric 2004, 7:375-389.

40. Oldenhave A, Jaszmann $\sqcup$, Haspels AA, Everaerd WT: Impact of climacteric on well-being. A survey based on 5213 women 39 to 60 years old. Am J Obstet Gynecol 1993, 168:772-780

41. Dennerstein L, Dudley EC, Hopper JL, Guthrie JR, Burger HG: A prospective population-based study of menopausal symptoms. Obstet Gynecol 2000, 96:351-358.

42. Dhillon HK, Singh HJ, Shuib R, Hamid AM, Mohd Zaki Nik MN: Prevalence of menopausal symptoms in women in Kelantan, Malaysia. Maturitas 2006, 54:213-221.

43. Ismael NN: A study on the menopause in Malaysia. Maturitas 1994, 19:205-209.

44. Peeyananjarassri K, Cheewadhanaraks S, Hubbard M, Zoa MR, Manocha R, Eden J: Menopausal symptoms in a hospital-based sample of women in southern Thailand. Climacteric 2006, 9:23-29.

45. Ho SC, Gaen CS, Bing YY, Yee CS, Sham A: Factors associated with menopausal symptom reporting in Chinese midlife women. Maturitas 2003, 44:149-156.

46. Porter M, Penney GC, Russell D, Russell E, Templeton A: A population based survey of women's experience of the menopause. Br J Obstet Gynaecol 1996, 103:1025-1028.

47. Budakoglu II, Ozcan C, Eroglu D, Yanik F: Quality of life and postmenopausal symptoms among women in a rural district of the capital city of Turkey. Gynecol Endocrinol 2007, 23:404-409.

48. Polit DF, LaRocco SA: Social and psychological correlates of menopausal symptoms. Psychosom Med 1980, 42:335-345.

49. Heinemann LA, DoMinh T, Strelow F, Gerbsch S, Schnitker J, Schneider HP: The Menopause Rating Scale (MRS) as outcome measure for hormone treatment? A validation study. Health Qual Life Outcomes 2004, 2:67.

Pre-publication history

The pre-publication history for this paper can be accessed here: http://www.biomedcentral.com/1472-6874/11/30/prepub

doi:10.1186/1472-6874-11-30

Cite this article as: Chuni and Sreeramareddy: Frequency of symptoms, determinants of severe symptoms, validity of and cut-off score for Menopause Rating Scale (MRS) as a screening tool: A cross-sectional survey among midlife Nepalese women. BMC Women's Health 2011 11:30.

\section{Submit your next manuscript to BioMed Central and take full advantage of:}

- Convenient online submission

- Thorough peer review

- No space constraints or color figure charges

- Immediate publication on acceptance

- Inclusion in PubMed, CAS, Scopus and Google Scholar

- Research which is freely available for redistribution

Submit your manuscript at www.biomedcentral.com/submit
Biomed Central 